\title{
INSTAGRAM SEBAGAI MEDIA PUBLIKASI DALAM MEMBANGUN BRAND AWARENESS JAKARTA AQUARIUM
}

\author{
Shintadevy Maryolein, Nadya Dwina Hapsari, Rani Chandra Oktaviani \\ shintadevymaryolein@gmail.com; nadyadwinahapsari@gmail.com; \\ rani.co@1spr.edu \\ Sekolah Tinggi Ilmu Komunikasi London School of Public Relations
}

\begin{abstract}
Jakarta Aquarium is an ex-situ conservation and education institution located in Neo Soho Mall, West Jakarta. As a newly established institution, Jakarta Aquarium wants its brand to be used by the wider community. The efforts made by the Public Relations Jakarta Aquarium are to utilize the features available on Instagram. The purpose of this research was to find out strengths and weaknesses the utilization of Instagram as a media publication for Jakarta Aquarium to build brand awareness. The theory used in this study is new media theory and supported by Public Relations concepts, publication concepts, and Instagram. This study uses a qualitative descriptive method that designed by data collection techniques in the form of structured interviews, literature studies and internet reviews, especially on Instagram Jakarta Aquarium activities. The findings obtained in this study are the use of Instagram has maximized Instagram's role as a platform to media publicity, consistent in managing the feed display and upload interesting content so that it can build Jakarta Aquarium's brand awareness in the wider community. In addition, through this research the researcher can find out more about the advantages of the Jakarta Aquarium's Instagram that has made it easier for people to access all information quickly and easily, and establish two-way communication with their followers. Also, the disadvantages of Jakarta Aquarium's Instagram that still uploads more promotional content than the educational content on Instagram.
\end{abstract}

Keywords: Communication, Instagram, New Media, Publication, Public Relations

\begin{abstract}
ABSTRAK
Jakarta Aquarium merupakan lembaga konservasi dan edukasi $e x$-situ yang terletak di dalam Mall Neo Soho, Jakarta Barat. Sebagai lembaga yang baru berdiri, Jakarta Aquarium ingin agar brand-nya dikenal oleh masyarakat luas. Bentuk upaya yang dilakukan Public Relations Jakarta Aquarium yakni memanfaatkan fitur-fitur yang ada di Instagram. Tujuan penelitian ini adalah untuk mengetahui kelebihan dan kekurangan pemanfaatan Instagram sebagai media publikasi Jakarta Aquarium dalam membangun brand awareness. Teori yang digunakan dalam penelitian ini adalah teori media baru dan didukung oleh konsep Public Relations, konsep publikasi, dan Instagram. Penelitian ini menggunakan metode deskriptif kualitatif yang dirancang melalui teknik pengumpulan data berupa wawancara terstuktur,
\end{abstract}


studi literatur dan tinjauan internet khususnya pada aktifitas Instagram Jakarta Aquarium. Temuan yang didapatkan dalam penelitian ini adalah pemanfaatan Instagram sudah memaksimalkan platform Instagram sebagai media publikasi, konsisten dalam mengatur tampilan feed dan mengunggah konten yang menarik sehingga dapat membangun brand awareness Jakarta Aquarium pada masyarakat luas. Selain itu, melalui penelitian ini dapat ketahui secara lengkap mengenai kelebihan Instagram Jakarta Aquarium yang sudah memudahkan masyarakat untuk mengakses segala informasi dengan cepat dan mudah serta menjalin komunikasi dua arah dengan pengikutnya, sedangkan kekurangan Instagram Jakarta Aquarium yang masih lebih banyak mengunggah konten promosi dibandingkan dengan konten edukasi dalam Instagram.

\section{Kata Kunci: Komunikasi, Instagram, Media Baru, Publikasi, Public Relations PENDAHULUAN}

Teknologi pada dasarnya
bertujuan untuk membantu dan
memudahkan manusia dalam
memenuhi segala aspek kehidupan
dan kelangsungan hidupnya di zaman
modern ini. Sama halnya dengan
kemajuan teknologi informasi, segala
bentuk informasi dapat didapat secara
praktis kapanpun dan dimanapun.
Teknologi informasir dapat
dimaksudkan sebagai kegiatan
pengumpulan, pengolahan,
pengelolaan, penyimpanan,
penyebaran dan pemanfaatan suatu informasi. Perkembangan teknologi informasi dapat meningkatkan kinerja dan memungkinkan berbagai kegiatan dapat dilaksanakan dengan cepat, tepat, dan akurat, sehingga dapat meningkatkan produktifitas kinerja. (Nuryanto, 2012:1-3)

\begin{tabular}{|c|c|}
\hline 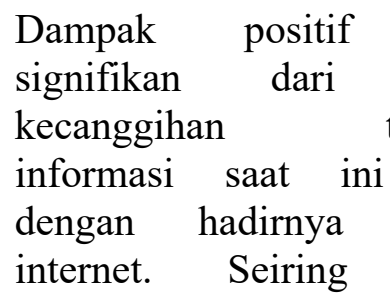 & $\begin{array}{r}\text { paling } \\
\text { adanya } \\
\text { teknologi } \\
\mathrm{i} \text { adalah } \\
\text { jaringan } \\
\text { dengan }\end{array}$ \\
\hline
\end{tabular}

perkembangan waktu, bentuk interaksi yang terjalin saat ini lebih mengarah kepada komunikasi digital melalui jaringan internet. Dalam ejurnal Acta Diurna dinyatakan bahwa internet menjadi salah satu sumber daya informasi yang cukup potensial untuk mempermudah sistem kehidupan. Hadirnya internet dianggap mampu melahirkan sebuah sistem kehidupan baru yang lain yaitu dunia maya. Dunia maya memiliki kemiripan yang jelas dengan kehidupan nyata. Segala sesuatu yang dilakukan di dunia nyata, dapat juga dilakukan di dunia maya (Talika, 2016:2).

Sama halnya dengan keberadaan media sosial yang memerlukan jaringan internet untuk mengaksesnya. Media sosial begitu terlihat nyata bahkan keberadaannya membuat manusia di era millennial ini terpaku untuk terus mengaksesnya. Dapat dibayangkan, segala bentuk kegiatan dalam dunia 
nyata kini berpindah platform ke media digital, mulai dari sekedar untuk berkomunikasi, belajar, mencari informasi hingga proses jual beli pun dapat dilakukan lewat media sosial.

Data dari Hootsuite dan We Are Social tahun 2017 menyatakan bahwa Indonesia memiliki 106 juta pengguna media sosial dari 262 juta pengguna internet yang tersebar di seluruh penjuru Indonesia. Dari datadata tersebut, hal ini menjadi suatu pernyataan bahwa tingginya pengguna media sosial tersebut juga dirasa memiliki potensi yang baik dalam pertumbuhan serta kemajuan ekonomi digital di Indonesia, sehingga tidak mengherankan apabila setiap perusahaan atau badan usaha berlomba-lomba untuk menggunakan media sosial dengan sebaik-baiknya (https://thenextweb.com/contributors /2017/04/11/current-global-stateinternet/).

Tujuan dari penggunaan media sosial dari masing-masing perusahaan pun beragam. Dilansir dari Jurnal Maskoolin, terdapat lima peran penting media sosial bagi perusahaan diantaranya, yaitu untuk meningkatkan interaksi antara perusahaan dengan konsumen, membantu dalam hal survei, meningkatkan Brand Awareness dan User Engagement, memudahkan viral marketing, dan memangkas banyak biaya (Dewi, 2016).
Abdullah dan Tantri (2012:32) menyatakan jika sebuah merek atau brand akan diluncurkan, maka media sosial digunakan untuk menyebarkan informasi yang sifatnya membuat pengikutnya menjadi penasaran. Dengan begitu, nama merek atau brand tersebut akan terdongkrak dan banyak dicari atau ditunggu orang. Namun, walaupun terintegrasi efektivitas pemanfaatan media sosial tetap tergantung pada pemilik merek atau brand itu sendiri. Media sosial bukan sekadar alat yang terkait dengan komunikasi global atau sekadar perkembangan tren teknologi, seperti memiliki akun Facebook, Twitter, Instagram dan lain sebagainya. Tetapi, hal ini akan berdampak pada semua kalangan perusahaan atau pebisnis, karena khalayak akan lebih dan semakin selektif dalam memilih produk atau jasa yang mereka butuhkan.

Dari sekian banyak media sosial hanya beberapa diantaranya yang memiliki jumlah pengguna aktif paling banyak sampai saat ini. Menurut hasil survei APJII di tahun 2016, tiga media sosial yang paling sering dikunjungi oleh masyarakat Indonesia adalah Facebook, Instagram dan Youtube (https://www.liputan6.com/tekno/rea d/2634027/3-media-sosial-favoritpengguna-internet-indonesia).

Dari ketiga media sosial tersebut, Instagramlah yang sampai saat ini berkembang pesat dengan 
segala inovasi fitur-fitur baru yang terus bermunculan, yaitu dengan adanya Instastory, fitur simpan (archive), inner circle, dan Instagram promote. Seperti yang dimuat dalam maxmanroe.com mengenai 7 fakta keunikan Instagram yang perlu diketahui oleh Internet Marketer, yakni brand besar juga hadir di Instagram, followers yang melimpah, penggunaan mention ternyata efektif, caption singkat ternyata tak buruk, brand yang mencantumkan lokasi, hashtag turut memengaruhi engagement, dan posting yang keren belum tentu cepat dikomentari (https://www.maxmanroe.com/7-

fakta-unikinstagram-yang-perlu-

diketahui-oleh-internet-

marketer.html).

Lebih jelasnya Instagram kini secara tidak langsung berubah menjadi media publikasi yang digunakan baik untuk kepentingan individu ataupun perusahaan dalam memopulerkan akun, brand, bahkan dalam membangun brand awareness. Instagram menjadi salah satu platform yang kompatibel dan menjadi salah satu aspek yang mendapat perhatian mendalam bagi para individu maupun perusahaan jika diaplikasikan di era modern saat ini. Walid (2018) menyatakan kelebihan dari pemasaran menggunakan media Instagram adalah bahwa Instagram memiliki keunggulan dalam konektivitasnya dengan media sosial popular lainnya seperti Twitter dan
Facebook. Cukup dengan klik kamera handphone, foto bisa langsung dibagikan ke Facebook dan Twitter.

Salah satu perusahaan di Indonesia yang memanfaatkan media sosial sebagai media publikasi adalah PT. Jakarta Akuarium Indonesia (Jakarta Aquarium). Jakarta Aquarium merupakan sebuah tempat hiburan keluarga baru yang mengedepankan konsep menggabungkan empat unsur penting, yaitu sebagai tempat konservasi, rekreasi, edukasi dan didukung oleh teknologi canggih. Sebagai sebuah tempat hiburan baru, tentunya Jakarta Aquarium memiliki keunikan lain, yaitu dengan mengedepankan konsep butik akuarium mini dalam mall maka menjadikan Jakarta Aquarium sebagai salah satu tempat wisata yang dapat diakses dengan mudah dan dapat dikunjungi oleh siapa saja.

$$
\text { Jika dikaitkan dengan }
$$

penggunaan media sosial dalam membangun brand awareness maka sebagai perusahaan baru guna memperkenalkan brand Jakarta Aquarium ke publik, perlu adanya konsep serta konten menarik untuk dibagikan ke media sosial dan website yang digunakan, sehingga masyarakat dapat mengetahui lebih dalam tentang Jakarta Aquarium itu sendiri. Branding berbicara mengenai bagaimana partisipasi kosumen dengan konsumen lainnya didalam jejaring sosial, dimana percakapan 
yang dilakukan antar konsumen tersebut akan berkembang (Mardalis dan Hastuti, 2017).

Hingga saat ini Jakarta Aquarium memiliki empat media publikasi online, yaitu Instagram, Facebook, Youtube, dan Website. Namun, dalam penerapannya hanya Instagram dan Website yang masih tetap aktif hingga saat ini, dengan kata lain media sosial yang ada hanyalah Instagram, sehingga peran Instagram menjadi penting bagi Jakarta Aquarium.

Dari latar belakang yang telah dijelaskan, tertarik untuk melakukan penelitian mengenai bagaimana Jakarta Aquarium menggunakan Instagram sebagai media publikasi untuk membangun branding. Sedangkan tujuan dari penelitian ini adalah untuk dapat mengetahui kelebihan dan kekurangan pemanfaatan Instagram sebagai media publikasi Jakarta Aquarium dalam membangun Brand Awareness. Melalui pemanfaatan Instagram yang telah dilakukan oleh Jakarta Aquarium nantinya dapat dilihat perbedaan yang signifikan yang membedakan Jakarta Aquarium dengan kompetitor di industri serupa dan di sisi lain agar melalui adanya pemanfaatan Instagram yang dilakukan oleh Jakarta Aquarium dapat mengetahui sejauh mana Jakarta Aquarium sudah dikenal oleh masyarakat.

\section{METODE PENELITIAN}

Metode yang dipakai dalam penelitian ini, yaitu menggunakan metode kualitatif. Penelitian kualitatif merupakan metode penelitian yang berlandaskan pada filsafat postpositivisme, digunakan untuk meneliti pada kondisi obyek yang alamiah, (sebagai lawannya adalah eksperimen) dimana peneliti adalah sebagai instrumen kunci, teknik pengumpulan data dilakukan secara triangulasi (gabungan), analisis data bersifat induktif atau kualitatif, dan hasil penelitian kualitatif lebih menekankan makna dari pada generalisasi. (Sugiyono, 2017:9)

Penelitian ini mengkaji secara menyeluruh dan utuh terkait media sosial Instagram sebagai media publikasi yang digunakan oleh Public Relations (PR) Jakarta Aquarium. Teknik pengumpulan data dalam penelitian ini menggunakan data primer melalui wawancara dan sekunder melalui studi literatur dan internet dengan melakukan pengamatan terhadap Instagram Jakarta Aquarium.

Teknik pengumpulan data melalui wawancara merupakan tahap paling awal yang dilakukan oleh peneliti dengan bertanya langsung kepada narasumber atau key informan yang kredibel untuk penelitian ini, sehingga diharapkan data yang diperoleh nantinya dapat dipertanggungjawabkan keabsahannya. Jenis wawancara yang 
peneliti gunakan dalam penelitian ini, yaitu wawancara terstruktur.

Adapun narasumber yang dituju, yaitu: 2 orang narasumber internal dari Jakarta Aquarium: Pertama, Helin Soenyono selaku PR dan Media Relations Jakarta Aquarium dan Kedua, Jonathan Setiawan selaku Graphic Designer Jakarta Aquarium; dan 3 orang narasumber eksternal yang merupakan followers Instagram Jakarta Aquarium: Pertama, Avad dan Kedua, Adisti selaku followers Instagram Jakarta Aquarium serta keduanya pernah menjadi PR Consultant bagi Jakarta Aquarium dan Ketiga, Albert selaku followers Instagram Jakarta Aquarium yang berprofesi sebagai Aquarist.

Teknik analisis data dalam penelitian ini menggunakan model Miles \& Huberman, yang terdiri dari 3 hal utama, yaitu reduksi data, penyajian data, dan verifikasi data (Sugiyono, 2017:246-253). Teknik kepercayaan data dalam penelitian ini, menggunakan teknik triangulasi sumber data, yaitu penggalian informasi tertentu melalui berbagai metode dan sumber data, seperti melalui wawancara, observasi atau dokumen tertulis. Masing-masing cara dapat menghasilkan data yang berbeda sehingga dapat memberikan pandangan yang berbeda mengenai fenomena yang diteliti. Berbagai pandangan itu dapat menciptakan keluasan pengetahuan untuk memperoleh kebenaran handal. (Pawito, 2007:100).

\section{HASIL DAN PEMBAHASAN}

Hasil penelitian ini menunjukkan hasil sebagai berikut:

Dalam bagian ini, peneliti membahas mengenai temuan dalam penelitian, yaitu mengenai pemanfaatan Instagram berdasarkan pada 4 karakteristik Instagram menurut @mrbambang (2012), yaitu followers, likes, comment, dan mention, serta 6 karakteristik teori media baru menurut Lister, Dovey, Giddings, Grant, \& Kelly (2009) yang terdiri dari digital, interactive, hypertextual, virtual, networked, dan simulated. 


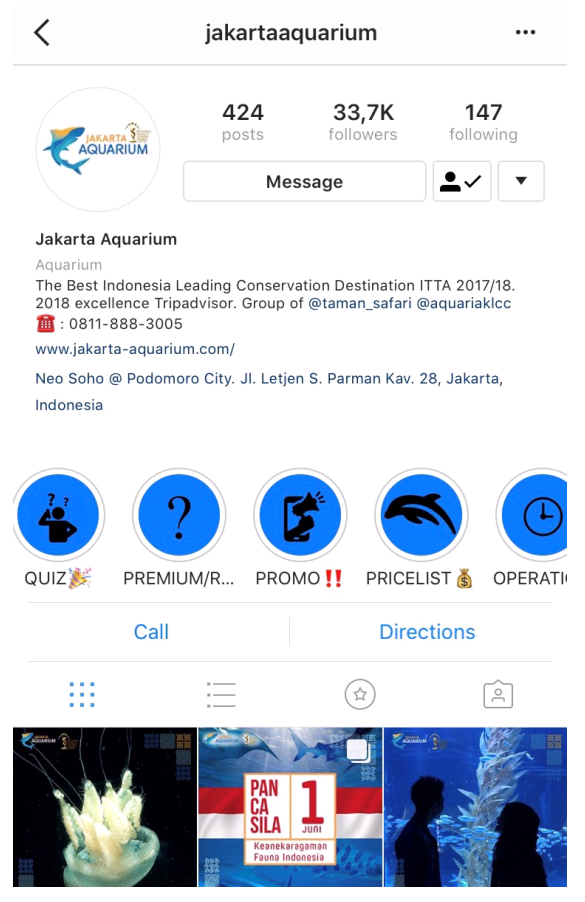

\section{Gambar 1 Tampilan Instagram Jakarta Aquarium}

A. Karakteristik Instagram Jakarta Aquarium dari aspek Followers

Jakarta Aquarium tidak

memiliki kekurangan pada aspek followers di akun Instagramnya. Sedangkan, kelebihan dalam akun Instagram Jakarta Aquarium adalah sebagai berikut:

Instagram Jakarta Aquarium telah menerapkan strategi Public Relations yang berdasarkan pada kontinuitas dan konsistensi melalui timeline planning untuk setiap konten yang diunggah dalam Instagram, sehingga dapat menarik pengguna Instagram untuk mengikuti (follow) Instagram Jakarta Aquarium. Seperti yang disampaikan oleh Helin, PR Jakarta Aquarium sebagai berikut:

"Bagaimana cara PR
mengembangkan followers'
yang pasti Jakarta Aquarium
harus komit dengan kontennya,
dan kontennya sendiri di sini
sudah dibuat timeline. Per-
minggu sudah ada. Karena
Jakarta Aquarium itu
Conservation Education, pasti
isinya tentang education
sehingga tidak melenceng
kontennya. Bagaimana kita bisa
mengembangkan followers,
Jadi, ya karena dalam konten-
kontennya itu konsisten. Jadi,
masyarakat dapat mengetahui
setiap harinya informasi apa
yang ada dalam Instagram
Jakarta Aquarium, misalnya
hari Senin ada konten fun fact,


hari Rabu ada Instagram Live by Education, jadi ya sudah pasti kalau orang-orang suka, mereka pasti akan menunggu informasi dari kita, dan mereka pasti follow juga, dan rekomen ke temen-temennya." (Helin, wawancara data primer, Maret 28, 2018)

Selain penerapan strategi Public Relations melalui timeline planning, Jakarta Aquarium juga memanfaatkan fitur digital promotion pada Instagramnya secara maksimal untuk mengiklankan platform Instagramnya ke berbagai media sosial lainnya, seperti iklan di Instagram, Facebook, Youtube, Websites, Google, dan lainnya. Melalui pemanfaatan digital promotion, Instagram Jakarta Aquarium dapat diketahui dan diikuti oleh pengguna media sosial lainnya. Instagram Jakarta Aquarium telah memaksimalkan semua fitur yang ada dalam Instagram seperti penggunaan Hashtag, Instagram Live, dan Instagram Story untuk memudahkan pengguna Instagram lain mengikuti Instagram Jakarta Aquarium.

Jakarta Aquarium juga melakukan kerjasama berbentuk endorsement dengan selebriti dan Public Figure untuk dipublikasikan melalui Instagram Jakarta Aquarium maupun Instagram selebriti atau Public Figure terkait, untuk menggaungkan Instagram Jakarta Aquarium agar dapat diketahui dan diikuti oleh para pengguna Instagram lainnya. Seperti yang dikatakan oleh Avad yang pernah menjadi $P R$ Consultant Jakarta Aquarium sebagai berikut:

"Proses boosting Instagram
Jakarta Aquarium awalnya
merupakan program Adisty
dimana selebriti kita invite
untuk datang ke Jakarta
Aquarium lalu mereka akan
mem-posting di social media
mereka, secara tidak langsung
nama Jakarta Aquarium
terangkat dan bertambah
followers-nya, karena hasil
posting-an dari Instagram
selebriti atau influencer
tersebut." (Avad, wawancara
data primer, April 3, 2018).

B. Karakteristik Instagram Jakarta Aquarium dari aspek likes

Ditemukan beberapa kelebihan dan kekurangan pada akun Instagram Jakarta Aquarium sebagai berikut:

Kelebihan yang dimiliki Instagram Jakarta Aquarium adalah mendapatkan perolehan jumlah likes terbanyak yang terdapat pada konten Guest Photo Repost, konten promosi (discount), dan konten-konten hiburan lainnya. $P R$ Jakarta Aquarium selalu memantau segala perkembangan yang terjadi pada Instagram Jakarta Aquarium tak terkecuali dengan perkembangan Likes-nya. Rata-rata Likes yang diperoleh dalam setiap foto dan video 
di Instagram Jakarta Aquarium pun beragam, seperti yang disampaikan Helin sebagai berikut:

"Perolehan likes satiap foto atau video berbeda tergantung konten yang diangkat apa. Guest Photo Repost banyak dilikes oleh followers dapat bisa memperoleh ratusan likes, berbeda dengan konten conservation atau funfact yang hanya berkisar 50 likes, tetapi rata-rata likesnya sendiri dapat menyentuh angka 50-60." (Helin, wawancara data primer, Maret 28, 2018)

Kekurangan yang dimiliki Instagram Jakarta Aquarium adalah: 1) dalam data statistik (insight) pada akun Instagram Jakarta Aquarium menunjukkan jumlah Impressions sebanyak 194.277 dan Reach sebanyak 25.356. Berdasarkan kedua data tersebut seharusnya Instagram Jakarta Aquarium mampu mendapatkan jumlah likes yang lebih banyak di setiap kontennya dibandingkan hasil rata-rata jumlah likes yang didapat, yaitu hanya berkisar 50-100 likes di setiap kontennya. 2) Konten edukasi seperti fun facts mengenai satwa yang diunggah dalam Instagram Jakarta Aquarium dianggap kurang menarik sehingga hanya mendapat sedikit likes.

\section{Karakteristik Instagram Jakarta Aquarium dari Aspek Comment}

Dalam aspek ini ditemukan kelebihan dan kekurangan pada akun Instagram Jakarta Aquarium sebagai berikut:

Kelebihan Instagram Jakarta Aquarium dari segi comment, yaitu Instagram Jakarta Aquarium sudah memanfaatkan kolom komentar dengan baik, dibuktikan dari setiap komentar yang masuk baik itu pertanyaan, saran, pujian maupun kritikan akan direspon dan dibalas satu per satu. Komentar yang terdapat di Instagram Jakarta Aquarium lebih banyak mengarah kepada hal yang positif, contohnya saja komentar yang ditanyakan oleh Followers Instagram Jakarta Aquarium mengenai berbagai macam promosi harga tiket masuk Jakarta Aquarium. Helin menyatakan dalam merespon dan menjawab keluhan followers di kolom komentar yang tidak puas akan pelayanan di Jakarta Aquarium akan segera mendapat respon dari pihak Jakarta Aquarium, seperti pernyataan sebagai berikut:
"Responnya langsung ditanggapi saat itu juga dengan meminta email dan nomer telfon pihak yang bersangkutan untuk langsung ditanggapi." (Helin, data wawancara primer, Maret 28, 2018)

Sedangkan, kekurangan dalam Instagram Jakarta Aquarium dilihat dari segi comment adalah durasi waktu yang dibutuhkan untuk membalas komentar terbilang cukup 
lama, yaitu memakan waktu kurang lebih 24 jam, seperti yang disampaikan Albert salah satu followers Instagram Jakarta Aquarium sebagai berikut:

"Dibalas tetapi tidak langsung hari itu juga, kira-kira ada jeda dalam satu hari itu." (Albert, data wawancara primer, April 2, 2018)

Pemanfaatan Instagram yang memiliki basis digital, memandang perlunya merespon feedback dari komunikan atau masyarakat, dengan dua arah dan cepat dalam fitur yang disediakan. (Yumna Aisyah, 2018). Selain itu, responsiveness merupakan proses evaluasi penyebaran informasi, hal ini juga merupakan indikator untuk menilai bahwa publikasi telah tersampaikan kepada khalayak, termasuk melihat sejauh mana pemahaman khalayak tentang sebuah brand.

\section{Karakteristik Instagram Jakarta Aquarium dari Aspek Mention}

Dalam dimensi mention, Instagram Jakarta Aquarium hanya memiliki kelebihan, sebagai berikut:

Penggunaan fitur mention pada Instagram telah digunakan secara maksimal oleh Instagram Jakarta Aquarium maupun oleh pengguna Instagram lain terhadap Instagram Jakarta Aquarium. Bentuk mention tersebut berupa Instastory, posting maupun tag. Menurut Bambang (2012:67), mention merupakan cara bagi pengguna Instagram untuk saling memanggil atau menyapa pengguna Instagram lainnya. Mention ini juga merupakan salah satu cara berkomunikasi di Instagram, bentuk mention pun bisa lewat Instastory, kolom komentar, unggahan atau menandainya dari akun Instagram lain. Hal ini senada seperti yang dikatakan Helin sebagai berikut:

"Bentuk mention-nya bisa lewat Instastory, kolom komentar, posting-an atau tag dari akun Instagram lain." (Helin, wawancara data primer, Maret 28, 2018) 

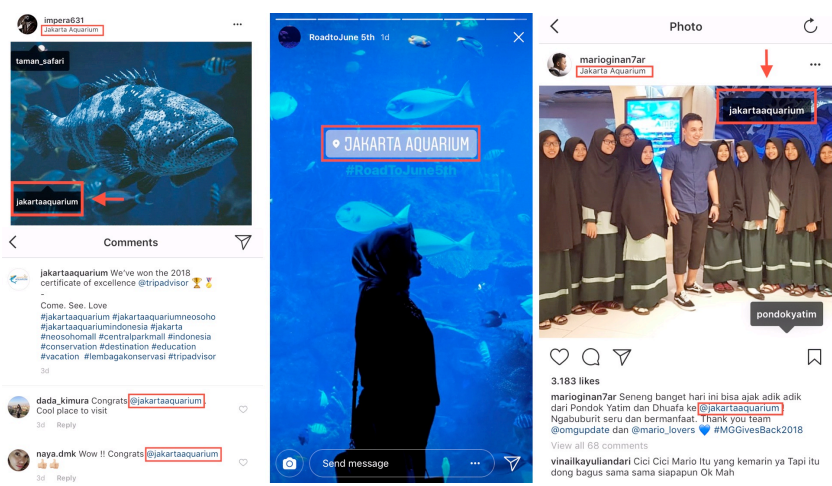

Gambar 2 Bentuk Interaksi Followers Pada Instagram Jakarta Aquarium.

\section{E. Kaitan dengan Teori Media Baru dan Sumbangan Teoretis \\ Terdapat enam karakteristik} New Media yang dijelaskan dalam buku New Media "A Critical Introduction Second Edition (Lister, Dovey, Giddings, Grant, dan Kelly, 2009:13), yakni Digital, Interactive, Hypertextual, Virtual, Networked, dan Simulated.

Dalam kaitan dengan teori media baru dalam unsur digital, menurut Lister et al. (2009:16) melalui karakteristik Digital semua data diolah menjadi angka dalam proses media digital. Dalam hal komunikasi dan media representasional, segala jenis data dikodekan menjadi bentuk-bentuk budaya seperti teks tertulis, grafik dan diagram, foto, gambar bergerak yang direkam, dan sebagainya.

Dalam penelitian ini karakteristik Digital berkaitan dengan pemanfaatan Instagram yang menjadi platform publikasi sebuah informasi agar dapat dipahami oleh khalayak luas agar sesuai dengan tujuan perusahaan. Melalui karakteristik ini peneliti mencoba memahami apa saja bentuk konten dan informasi yang dipublikasikan dalam Instagram Jakarta Aquarium.

Kelebihan yang ada pada Instagram Jakarta Aquarium dalam karakteristik Digital adalah 1) sebagai media publikasi, Jakarta Aquarium telah memublikasikan segala informasi sesuai dengan apa yang ingin dicapai oleh perusahaan yaitu memublikasikan tentang konten edukasi yang berisi fun facts seputar kehidupan satwa yang terdapat dalam Jakarta Aquarium dan konten promosi yang tengah berjalan, konten-konten tersebut dipublikasikan ke dalam Instagram Jakarta Aquarium. 2) segala informasi yang diunggah dalam Instagram Jakarta Aquarium sudah terjadwal dengan baik dengan adanya timeline planning, yaitu dengan menggunggah tiga posting setiap harinya. Senada dengan yang dikatakan Helin selaku $P R$ Jakarta Aquarium berikut ini:

"Ada, ada timeline planningnya, jadi diatur dari Senin sampai Minggu itu jamnya selalu ada di jam 11, jam 4 sore, 
sama jam 7 malam, karena dilihat dari report-reportnya itu diantara jam-jam itu yang likesnya banyak tapi walaupun di jam 11, jam 4 dan jam 7, terkadang agak meleset, misalnya lewat sekitar 5 menit. Yang pasti tidak boleh melebihi setengah jam. Kontennya sendiri sudah ter-timeline semuanya." (Helin, wawancara data primer, Maret 28, 2018)

Kekurangannya adalah 1) untuk saat ini Instagram Jakarta Aquarium masih lebih banyak mengunggah konten promosi dibandingkan konten edukasi, sehingga belum sesuai dengan tujuan dan cita-cita perusahaan yang ingin lebih mengedepankan konten edukasi dibandingkan konten promosi. 2) Instagram Jakarta Aquarium masih belum terlalu merepresentasikan Jakarta Aquarium sebagai lembaga konservasi dan edukasi tetapi hanya sebatas pada sarana hiburan saja. Seperti yang disampaikan oleh salah satu followers Instagram Jakarta Aquarium seperti berikut:

"Sebenarnya tergantung, relative-ya kalau bagus atau tidaknya itu, bagus secara desain grafis... sudah bagus. Secara marketing mungkin Jakarta Aquarium pun juga sudah bagus, jadi kalau memang menilainya hanya untuk marketing sudah bagus jadi yang kita bilang adalah dari sisi education-nya kan yang kurang atau conservation-nya atau awareness, $\mathrm{hmm}$ isu awareness bukan brand awareness ya itu beda lagi kan. Lebih ke isu conservation awareness, itu sih yang kurang tapi untuk kontennya sendiri ya tergantung marketing strategynya apa kalau itu relative bagus sih. Udah bagus kalau sekarang." (Adisty, wawancara data primer, April 3, 2018)

Menurut Lister et al. (2009:21) Interactive merupakan salah satu nilai utama yang terdapat pada media baru. Melalui karakteristik ini media lama menawarkan penawaran pasif, sedangkan media baru menawarkan interaktivitas yang mewakili rasa keterlibatan pada penggunanya. Segala bentuk komunikasi yang terjalin menjadi lebih aktif dan dapat mudah digunakan dengan menggunakan jaringan internet.

Dalam penelitian ini karakteristik Interactive berkaitan dengan bagaimana bentuk dan cara interaksi yang digunakan dalam Instagram Jakarta Aquarium terhadap pengguna Instagram lainnya.

Kelebihan dan kekurangan pemanfaatan Instagram Jakarta Aquarium dalam karakteristik Interactive sebagai berikut: Kelebihannya adalah 1) bentuk interaksi antara Instagram Jakarta Aquarium dengan pengguna Instagram lainnya sudah interaktif dan sudah terjalin dua arah, yaitu berupa live story, melalui kolom komentar, dan direct message. Segala 
bentuk informasi yang disampaikan sudah sesuai dengan tujuan utama perusahaan, yakni tidak hanya sebagai media informasi biasa melainkan dapat menambah pengetahuan bagi masyarakat. 2) memiliki satu pengelola khusus yang bertugas untuk membalas segala pesan yang masuk ke Instagram Jakarta Aquarium.

Seperti pernyataan Helin selaku $P R$ Jakarta Aquarium sebagai berikut:

"Berupa Live Story Instagram, komen, dan Direct Message. Komunikasinya dua arah." (Helin, wawancara data primer, Maret 28, 2018).

Selain $P R$ yang bertanggung jawab untuk mengelola akun Instagram Jakarta Aquarium, terdapat satu pengelola yang khusus bertanggung jawab untuk membalas segala pesan yang masuk ke Instagram Jakarta Aquarium. Pengelola tersebut merupakan mahasiswa yang sedang menjalani program magang di Jakarta Aquarium, seperti yang disampaikan Helin berikut ini:

"Pesannya dapat dibalas saat itu juga. Langsung dibalas, karena admin-nya juga bekerja dengan cepat. Admin-nya Stephanie, dia anak magang dari Prasmul baru semester satu. Dia tidak pernah kesini tapi dia khusus untuk membalas pesan Instagram saja." (Helin, wawancara data primer, Maret 28, 2018)
Kekurangannya adalah 1) durasi waktu yang dibutuhkan untuk membalas pesan masih belum konsisten, terkadang cepat bisa juga lambat dalam kurun waktu maksimal satu hari. 2) bentuk interaksi yang terjalin sudah cukup baik tetapi masih terdapat sebagian komentar yang belum sesuai dengan ekspektasi Jakarta Aquarium, yaitu dengan adanya interaksi seputar edukasi satwa yang berada dalam Jakarta Aquarium.

Menurut Lister et al. (2009:25) Hypertextual berkaitan dengan data atau informasi yang terdapat pada media lama dimasukkan kembali dan disajikan menyesuaikan dengan tampilan media baru.

Dalam unsur Hypertextual, Jakarta Aquarium tidak memiliki kekurangan pada pemanfaatan Instagramnya. Sedangkan, kelebihan adalah sebagai berikut: 1) Instagram Jakarta Aquarium sudah menerapkan bentuk hypertextual dengan maksimal dibuktikan dengan memaksimalkan kolom biodata yang di dalamnya mencantumkan website, location, telephone, email dan directions, sehingga pengguna Instagram lain dapat mengetahui informasi lengkap tentang Jakarta Aquarium. 2) melakukan digital promotion pada media sosial dengan menyertakan referensi link website dan Youtube Jakarta Aquarium, sehingga diharapkan dapat 
memudahkan pengguna Instagram lain untuk menjangkau segala jenis media sosial yang dimiliki Jakarta Aquarium. 3) Instagram Jakarta Aquarium telah memanfaatkan fitur hashtag, geo tagging, dan person tagging secara maksimal sehingga setiap konten yang diunggah dapat sesuai dengan konsep dan tujuan utama Jakarta Aquarium.

Hal tersebut didukung dengan pernyataan Albert selaku followers Instagram Jakarta Aquarium sebagai berikut:

"Sudah ya karena sudah cukup detail-lah karena kan lokasi tempat yang penting sudah ada semua." (Albert, wawancara data primer, April 2, 2018)

Pernyataan Albert tersebut didukung dengan pernyataan Avad yang menyatakan kalau Instagram Aquarium telah memanfaatkan kolom biodata secara maksimal dengan mencatumkan website, location, telephone, directions, dan email sehingga menurutnya para pengguna Instagram lain dapat mengetahui informasi lengkap tentang Jakarta Aquarium. Berikut pernyataannya:

"Secara tidak langsung kan jadi tau, dan dengan begitu jadi ikut tergiring ke website juga." (Avad, wawancara data primer, April 3, 2018)

Menurut Lister et al. (2009:35) Virtual berkaitan dengan mewujudkan dunia virtual yang diciptakan oleh keterlibatan grafik computer dan video digital. Virtual juga berfungsi sebagai identitas postmodern, seni, hiburan, konsumen, dan budaya visual, sehingga apa yang ditampilkan di dunia nyata dapat dilihat pada dunia maya.

Melalui karakteristik virtual ini, Instagram Jakarta Aquarium memanfaatkan fitur Instastory dan Live Instagram sebagai media virtual, kedua fitur tersebut berguna untuk memperkenalkan Jakarta Aquarium dan memberikan informasi yang lengkap tentang kehidupan satwa dan kualitas karyawan yang ada pada Jakarta Aquarium.

Kelebihan dan kekurangan pemanfaatan Instagram Jakarta Aquarium dalam karakteristik Virtual adalah sebagai berikut: Kelebihannya adalah 1) pemanfaatan Instagram melalui fitur instastory dan live Instagram sebagai media virtual berguna untuk memperkenalkan Jakarta Aquarium dan cukup memberikan informasi yang lengkap tentang kondisi satwa yang terdapat di Jakarta Aquarium sekaligus menunjukkan kualitas para karyawan yang bekerja di sana. 2) dalam membuat konten video atau foto untuk diunggah ke Instagram, Jakarta Aquarium memakai semua foto dan video milik Jakarta Aquarium pribadi, dan mengedepankan konsep fresh thing (baru dan kekinian) sehingga membedakan dengan kompetitor lain. 
Kekurangannya adalah 1) beberapa konten yang diunggah melalui fitur live Instagram dan instastory dianggap terlalu over expose sehingga yang ditakutkan nantinya tidak menarik minat masyarakat untuk datang ke Jakarta Aquarium. 2) konten yang diunggah melalui fitur live Instagram dan instastory masih dianggap kurang bervariasi seharusnya dapat dibuat lebih beragam seperti dengan mengutamakan informasi yang dapat berupa story telling untuk menjelaskan satwa-satwa yang terdapat di Jakarta Aquarium. 3) konten foto dan video yang diunggah dalam Instagram Jakarta Aquarium dianggap belum terlalu merepresentasikan identitas Jakarta Aquarium sebagai lembaga konservasi dan edukasi.

Seperti pernyataan yang disampaikan Albert selaku followers Instagram Jakarta Aquarium berikut ini:

"Bermanfaat, karena itu juga menunjukkan secara langsung ada apa saja hewan-hewan yang ada di sana dan juga menunjukan kualitas dari karyawan-karyawan yang ada di Jakarta Aquarium, kalau memang berkompeten di bidangnya. Tapi memang terkadang pernah didapat beberapa kali memang terlalu over expose ya. Jadi sangat disayangkan sebenarnya, jadi lebih baik sedikit diatur angle yang diambil atau hewannya apa dengan begitu pasti akan membuat orang lebih tertarik karena jadi harus datang untuk melihat secara langsung." (Albert, wawancara data primer, April 2, 2018)

\section{Adisty selaku followers Instagram Jakarta Aquarium sekaligus pernah menjadi $P R$ Consultant untuk Jakarta Aquarium menambahkan:}

"Kontennya itu yang harusnya dijual, yaitu si ikan-ikan itu. Harusnya lebih banyak lagi seperti: "Karakter ikan ini seperti apa, karakternya binatang ini seperti apa, disampaikan melalui Instastory dan seharusnya bisa dijadikan Story Telling. Itu yang menarik, kalau kita lihat dan kita bandingkan dengan AquariumAquarium lain yang sudah cukup besar di USA seperti Monterey Bay Aquarium, Shedd Aquarium, mereka pakai itu. Jadi, salah satu upaya yang dipakai untuk di-posting dengan menampilkan setiap ikan-ikan yang berbeda atau binatang-binatang yang berbeda di Instastory. Jadi, setiap hari ada kontennya, karena binatangnya banyak dan beragam." (Adisty, wawancara data primer, April 3, 2018)

Menurut Lister et al. (2009:30) Networked bertujuan untuk mempermudah penggunanya memperluas jaringan mereka dengan cakupan yang lebih luas. Jaringan tersebut antara lain World Wide Web 
(WWW), situs media sosial, situs web $b l o g$, forum online, situs web edukasi dan sebagainya. Pada kesempatan ini karakteristik networked dapat juga berupa adanya proses hubungan atau bentuk kerjasama suatu pihak dengan berbagai pihak lainnya.

Kelebihan dan kekurangan pemanfaatan Instagram Jakarta Aquarium dalam karakteristik Networked adalah sebagai berikut: Kelebihannya adalah Jakarta Aquarium telah bekerjasama dengan beberapa Public Figure, NGO, Komunitas, Pemerintah, Partnership, Sponsorship dan sebagainya melalui platform Instagram dalam memperkenalkan dan memublikasikan Jakarta Aquarium pada masyarakat.

Seperti yang disampaikan Helin selaku $P R$ Jakarta Aquarium sebagai berikut:

"Kalau untuk bentuk kerjasamanya sendiri misalnya untuk public figure itu kita sering mengundang mereka bahkan tanpa diundang pun mereka sering datang ke Jakarta Aquarium. Jadi, misalnya ada artis yang datang dan misalkan aku ada di kantor biasanya kita minta public figure tersebut untuk take over Instagram Jakarta Aquarium lewat Instastories untuk mengajak viewers untuk datang juga ke Jakarta Aquarium sekaligus mempromosikan Jakarta Aquarium. Kalau untuk komunitas sering juga buat event-event bersama, kalau misalkan untuk NGO dan Pemerintah $P R$ dan tim education akan selalu mengirimkan report-report sosial media kita ke mereka. Sebagai tanggung jawab perkembangan Jakarta Aquarium." (Helin, wawancara primer, Maret 28, 2018)

Helin menambahkan:

"Ke WWF iya, terus ke pemerintahannya ada ke Kementerian Kehutanan, lingkungan hidup, sudah. Karena Jakarta Aquarium merupakan bagian dari Safari Group pasti kita ada kerja sama karena, hewan-hewannya banyak yang barter dari sana juga dan ada yang dikasih dari Taman Safari. "Kalau partnership ada banyak yang pernah kerja sama dengan kita, ada Tokopedia, ada Shopback, ada Coldstone ada Traveloka, ada kerja sama dengan beberapa bank. Kalau untuk artis sendiri kita pernah kerja sama dengan Raffi Ahmad, Chelsea Islan, Reza Chandika, Dipha Barus, Kunto Aji, Marchella, dan lain-lain.” (Helin, wawancara data primer Maret 28, 2018)

Kekurangannya adalah terkait dengan adanya kerja sama dengan berbagai pihak seharusnya Jakarta Aquarium lebih memperhatikan siapa saja yang terlibat, dengan kata lain, misalnya untuk kerja sama dengan Public Figure seharusnya lebih memerhatikan individu yang memang sesuai dengan tujuan dan perhatian 
utama perusahaan, yaitu Public Figure yang sering terlibat dalam kegiatan pelestarian alam dan pecinta satwa sehingga dapat selaras dengan visi-misi perusahaan, bukan hanya sebatas memilih Public Figure secara asal untuk diajak kerja sama. Seperti yang disampaikan Adisty selaku Followers Instagram Jakarta Aquarium sebagai berikut:

"Targeting-nya beda misalnya yang datang seperti Reza Chandika lagi, ya maksudnya memang Jakarta Aquarium butuh selebriti yang punya banyak followers, tapi kan alangkah baiknya kalau mereka bisa bekerjasama dengan selebriti yang lebih fokus ke course-nya maksudnya ya memang yang suka diving atau yang berhubungan dengan dunia laut. Jadi dapat sesuai." (Adisty, wawancara data primer, April 3, 2018)

Menurut Lister et al. (2009:38) Simulated merupakan sebuah representasi dari suatu peristiwa atau suatu kejadian, objek, atau hal lain yang dapat menambah pemahaman terhadap hal tersebut tanpa harus memasuki atau mengalami kejadian atau benda asli secara langsung. Dengan adanya virtualisasi dan teknologi digital, media baru dapat menghadirkan sebuah simulasi terhadap suatu objek atau suatu peristiwa tertentu.

$P R$ Jakarta Aquarium mencoba merepresentasikan Jakarta Aquarium melalui feed yang tertata rapi sesuai dengan guideline perusahaan sehingga tampilan Instagram Jakarta Aquarium nyaman untuk dilihat dan mudah untuk dibaca serta saat pengguna Instagram lain ketika melihat Instagram Jakarta Aquarium langsung dapat mengetahui kalau itu ciri khas yang dimiliki Instagram Jakarta Aquarium.

Kelebihannya adalah 1) tampilan (feed) Instagram Jakarta Aquarium sudah cukup baik secara grafis dan estetika. 2) Instagram Jakarta Aquarium dinilai sudah aktif dalam memublikasikan segala informasi yang ingin disampaikan. 3) Instagram Jakarta Aquarium sudah cukup sering memanfaatkan situasi yang sedang booming untuk menarik minat pengguna Instagram lain. 4) $P R$ Jakarta Aquarium sangat memerhatikan tampilan (feed) Instagram karena melalui feed yang dikemas secara baik dapat meningkatkan kesadaran masyarakat akan brand Jakarta Aquarium melalui Instagram.

Merek suatu produk haruslah dikomunikasikan dengan tepat agar bisa masuk ke dalam benak konsumen sehingga eksistensi merek dapat terbentuk. Komunikasi yang tepat dapat membantu menumbuhkan kesadaran merek secara optimal (Octavianti, 2012). Didukung dengan pernyataan Helin selaku $P R$ Jakarta Aquarium yang menyatakan jika strategi dalam menampilkan konten 
yang diunggah harus tertata dengan baik, berikut pernyataannya:

"Ya pasti jadi apa yang mau diposting ke Instagram itu PR akan kerjasama sama tim desain untuk mengelola feed-nya. Penggunaan feed-nya itu biar tertata jadi biar Instagram-nya tidak berantakan." (Helin, wawancara data primer, Maret 28, 2018)

Kekurangannya adalah 1) strategi PR Jakarta Aquarium dalam mengelola Instagram Jakarta Aquarium masih lebih banyak mencakup konten promosi (discount, sale, dan lain-lain) sehingga belum menggiring opini masyarakat untuk mengetahui bahwa yang ingin ditampilkan dalam Instagram Jakarta Aquarium sebenarnya adalah konten edukasi-nya. 2) melalui situasi yang sedang tren atau booming di tengah masyarakat, akan lebih baik jika Instagram Jakarta Aquarium tidak perlu mengikuti tren-tren tersebut jika tidak ada kaitannya dengan tujuan dan konsep utama perusahaan sebagai lembaga konservasi dan edukasi. 3) belum pernah ada kegiatan campaign yang dilakukan oleh Instagram Jakarta Aquarium. 4) konten yang diunggah dalam Instagram Jakarta Aquarium sudah cukup baik tetapi jika dibandingkan dengan Instagram kompetitor luar negeri masih dapat dikatakan cukup tertinggal karena belum mengutamakan konten edukasi sebagai identitas Instagram Jakarta Aquarium. Jika yang diangkat konten edukasi, mungkin saja akan menambah minat masyarakat untuk datang ke Jakarta Aquarium. 5) manajamen konten dinilai kurang berkelas dan sering terlambat dalam menggunggah konten (tidak sesuai timeline planning). Penguatan cara berkomunikasi dengan sudut pandang Public Relations, menjadi aspek penting yang dinilai dalam pemanfaatan Instagram Jakarta Aquarium.

Hal tersebut didukung dengan pernyataan Avad selaku Followers Instagram Jakarta Aquarium sebagai berikut:

"PR Activity-nya kurang. Jadi kalau aku bilang lebih ke Marketing karena sebenarnya tugasnya $P R$ Internal kan, dia harus membentuk opini di masyarakat untuk Jakarta Aquarium itu apa sih sebenarnya? Itu kan baru tugasnya $P R$ kan. Kalau sekarang lebih kepada promosi ini loh Jakarta Aquarium bukan membuat masyarakat berfikir menggiring opini bahwa oh Jakarta Aquarium itu adalah sarana edukasi, lembaga konservasi. Itu kan sebenarnya tugasnya $P R$ tapi sekarang lebih kepada marketing activity aja. Jadi, terkesan seperti ini ada Jakarta Aquarium loh, kamu dateng ke Jakarta Aquarium dapet promo ini loh dapat diskon juga untuk bisa ke Taman Safari, jadi mengarah ke hal seperti itu. Tapi untuk $P R$ Activity-nya aku bilang 
sekarang belum sih. Belum ada." (Avad, wawancara primer, April 3, 208)

Hasil penelitian ini, juga menekankan bahwa media baru khususnya sosial media Instagram mempunyai kekuatan tersendiri dalam membantu publikasi organisasi ataupun perusahaan. Dari keenam unsur media baru, yang telah dipaparkan baik dari aspek temuan dan juga kaitannya dengan implikasi penerapannya. Dinilai perlu adanya satu elemen yang mendukung unsur media baru, yakni people. People yang dimaksud adalah beberapa pihak yang secara aktif berperan dalam mengelola media baru tersebut, seperti diantaranya perancang strategi pesan dan design komunikasi visual Instagram, kemudian pihak yang secara teknis menjadi pengelola dalam mengelola Instragram setiap harinya, hal ini direkomendasikan untuk menyelaraskan penggunaan fungsi media baru yang aktif dan konsisten. Selain itu, diperlukannya pihak yang membantu perusahaan khususnya Jakarta Aquarium dalam mendongkrak publikasi dan pesan persuasive kepada khalayak seperti third party endorsement, selebritis Instagram, dan endoser yang dinilai sesuai dengan target khayakan dari Jakarta Aquarium. Sehingga selain dari enam aspek media baru yang ditelaah, dinilai bahwa sumber daya pengelola menjadi sumbangan teoretis yang direkomendasikan dalam penelelitian ini, bukan hanya sekedar dalam implementasi praktis. Namun, dalam pengembangan teoretis bahwa kekuatan publikasi tidak hanya dalam platform media barunya saja, namun kemampun, skill, dan keahlian dalam mengelola media baru menjadi konsentrasi yang perlu diperhatikan dan dipilih dengan seksama dalam pemanfaatan media baru.

\section{F. Pemanfaatan Instagram Jakarta Aquarium Dalam Membangun Brand Awareness \\ Dalam jurnal penelitian ini,} peneliti hanya menjabarkan secara singkat hubungan antara pemanfaatan Instagram Jakarta Aquarium sebagai publikasi dalam membangun Brand Awareness, karena fokus utama dalam penelitian ini, yaitu pada aspek pemanfaatan Instragram dan juga karakteristik teori Media Baru. Brand awareness atau kesadaran merek menurut Aaker (Rangkuti, 2009:39) merupakan kesanggupan seseorang calon pembeli untuk mengenali atau mengingatkan kembali bahwa suatu merek merupakan bagian dari kategori produk tertentu. Jika dikaitkan dengan kegiatan $P R$, menurut Rosady Ruslan (2001) (dalam Nurjaman dan Umam, 2012:113), tujuan Public Relations, yaitu untuk mendukung bauran pemasaran dan juga efektif dalam membangun pengenalan merek dan pengetahuan merek. 
PR Jakarta Aquarium yang berada dibawah naungan divisi Marketing Communication turut memiliki tanggung jawab yang besar dalam membangun brand awareness perusahaan. Instagram Jakarta Aquarium sendiri dikelola oleh $P R$ Jakarta Aquarium. Guna membangun Brand Awareness di Instagram, tentunya $P R$ menerapkan berbagai macam strategi agar masyarakat lebih mengetahui dan lebih mengenal tentang Jakarta Aquarium khususnya lewat media sosial Instagram. $P R$ Jakarta Aquarium memanfaatkan secara maksimal segala fitur yang ada di Instagram, hal ini didukung dengan segala macam konten yang dipersiapkan secara matang agar dapat menarik pengguna Instagram lainnya.

Kesadaran merek mengacu kepada kemampuan pelanggan potensial untuk mengenali atau mengingat suatu merek dari produk atau jasa (Levy dan Weitz, 2009:444). Jika dikaitkan dengan penelitian ini, brand Jakarta Aquarium berbentuk jasa dimana Jakarta Aquarium sebagai lembaga konservasi dan edukasi. Keberadaan Jakarta Aquarium sebagai tempat untuk menambah wawasan dan belajar mengenai kehidupan satwa yang terdapat di dalam Jakarta Aquarium itu sendiri. Melalui Instagram, Jakarta Aquarium mencoba untuk menampilkan brand-nya sebagai platform untuk mengedukasi masyarakat sama seperti tujuan dan konsep utama perusahaan.

Selain adanya tagline yang menarik, menurut Kartajaya (2010:65) untuk meningkatkan kesadaran merek, perusahaan juga perlu mengembangkan simbol yang memiliki keterkaitan erat dengan merek. Dalam konteks ini, Instagram Jakarta Aquarium sangat memerhatikan tampilan visual yang ada dalam Instagram-nya. Bukti nyatanya, yaitu dengan adanya beragam elemen visual seperti penggunaan logo, penggunaan warna yang konsisten, frame dan template untuk konten Instagram, penggunaan gambar animasi khusus, maskot, dan pemilihan font yang konsisten di setiap konten yang dipublikasikan.

Melalui gambar tersebut dapat dilihat bahwa setiap konten yang dipublikasikan dalam Instagram Jakarta Aquarium harus memerhatikan dengan baik setiap elemen visualnya, dan dalam pembuatan konten desainnya pun harus mengikuti guideline yang sudah ada. 

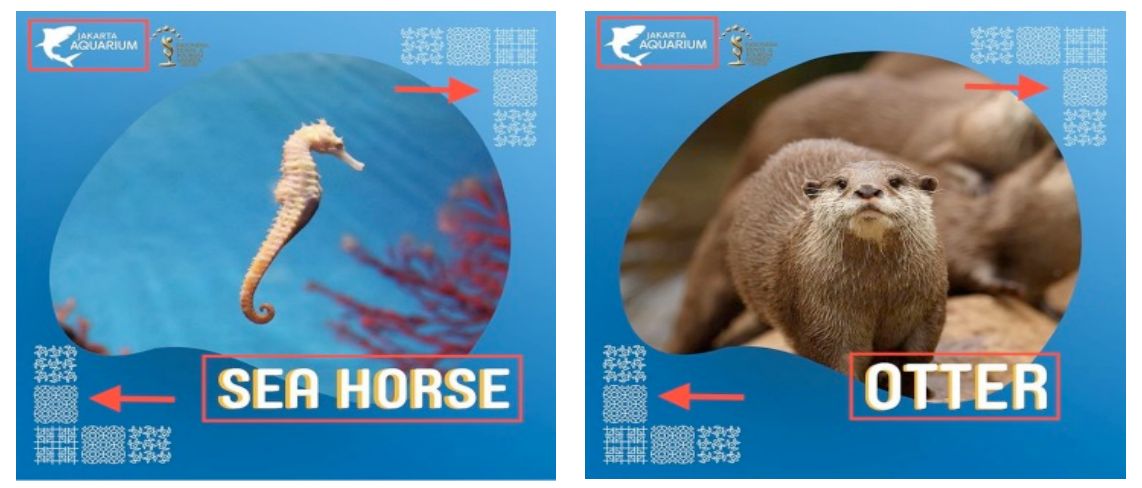

Gambar 3 Konten Visual di Instagram Jakarta Aquarium

Dengan begitu dapat disimpulkan bahwa Instagram Jakarta Aquarium sudah menata Instagramnya dengan baik melalui penataan feed yang baik akan tetapi, yang menjadi tujuan utama perusahaan itu sendiri belum tercapai, yaitu lebih mengutamakan konten edukasi dibandingkan konten promosi.

\section{SIMPULAN}

Sesuai dengan tujuan dalam penelitian ini, yaitu untuk mengetahui kelebihan dan kekurangan Instagram Jakarta Aquarium dalam membangun brand awareness maka kelebihan yang terdapat pada Instagram Jakarta Aquarium adalah segala konten yang diunggah pada Instagram sudah memudahkan masyarakat khususnya pengguna Instagram lain untuk menerima informasi dengan baik, akses yang mudah dan juga cepat, sehingga dapat dilihat khalayak luas. Komunikasi yang terjalin sudah dua arah antara Jakarta Aquarium dengan pengguna Instagram lainnya sehingga informasi yang telah disampaikan oleh Jakarta Aquarium dapat menambah pengetahuan bagi masyarakat dan menyebabkan Jakarta Aquarium mendapatkan umpan balik (feedback) dari masyarakat. Instagram Jakarta Aquarium telah memanfaatkan kolom biodata secara maksimal, dan live Instagram dinilai cukup berhasil untuk memberikan informasi dan edukasi seputar Jakarta Aquarium. Instagram Jakarta Aquarium dinilai sudah cukup baik, sehingga segala informasi yang disampaikan oleh Jakarta Aquarium dapat dipercayai oleh masyarakat, dan dengan dukungan kerja sama dari pihak-pihak seperti WWF, NGO, Public Figure, dan Influencer yang dapat menjangkau masyarakat lebih luas. Kekurangan pada Instagram Jakarta Aquarium, yaitu lebih banyak menggunggah konten promosi dibandingkan konten edukasi, dan kecepatan dalam membalas pesan dari followers dinilai cukup lambat, yaitu memakan waktu kurang lebih 24 jam, dan pemilihan partner yang kurang tepat seperti Public Figure atau Influencer yang memiliki 
perbedaan target dengan tujuan perusahaan untuk diajak bekerja sama.

\section{DAFTAR PUSTAKA}

\section{Buku:}

@ mrbambang. (2012). Instagram Handbook, Jakarta, Media Kita.

Abdullah, T., dan Tantri, F. (2012). Manajemen Pemasaran. Cet. Ke-1. Jakarta: Raja Grafindo Persada.sÉp.

Lister, M., Dovey, J., Giddings, S., Grant, I., dan Kelly, K. (2009). New Media A Critical Introduction. Second Edition. New York: Routledge.

McQuail, D. (2011). Teori Komunikasi Massa McQuail. Edisi 6. (P. I. Izzati, Trans). Jakarta: Penerbit Salemba Humanika.

Nuryanto, H. (2012). Sejarah

Perkembangan Teknologi Informasi dan Komunikasi. Jakarta Timur: PT Balai Pustaka (Persero).

Pawito. (2007). Penelitian Komunikasi Kualitatif. Yogyakarta. Pelangi Aksara: Yogyakarta.

Sugiyono. (2017). Metode Penelitian Kuantitatif, Kualitatif, dan $R \& D$. Bandung: Alfabeta.

\section{Sumber lain:}

Dewi, N. R. (2016, Juni 10). Maskoolin (2017, September
28). Diakses dari Maskoolin Website:

https://jurnal.maskoolin.com/j urnal/gayahidup/ culture/pentingnya-peransosial-media-untukperusahaan/

Fauzi, V. P. (2016). Pemanfaatan Instagram sebagai Sosial Media Marketing Er-Corner Boutique dalam membangun Brand Awareness. JOM FISIP Vol. 3 No.1.

Fauziah, \& Trenggana, A. M. (2016, Agustus). Pengaruh Penggunaan Social Media terhadap tingkatan brand Awareness HijUp.com di Kota Bandung. e-Proceeding of Management: Vol.3, No.2.

Indika, dan Jovita, C. (2017). Media Sosial Instagram Sebagai Sarana Promosi Untuk Meningkatkan Minat Beli Konsumen. Jurnal Bisnis Terapan Vol. 01, No. 01.

Mardalis, A., \& Hastuti, A. P. (2017). Pemanfaatan Media Sosial Untuk Membangun Kepercayaan Merk. Prosiding "Perkembangan Konsep dan Riset E-Business di Indonesia". Seminar Nasional Riset Manajemen \& Bisnis 2017.

Maxmanroe.com. (n.d.). Maxmanroe.com (2017, September 28). Diakses dari Maxmanroe Website: 
https://www.maxmanroe.com /7-fakta-unikinstagram-yangperlu-diketahui-oleh-internetmarketer.html

Octavianti, M. (2012). Menumbuhkan Kesadaran Merek Produk Melalui Media SosialisêpiStudi Kasus Mengenai Optimalisasi Penggunaan "Twitter" Sebagai Upaya Menumbuhkan Kesadaran Merek Maicih "Keriping Singkong Pedas Asli Kota Bandung”. Jurnal Ilmu Komunikasi, Vol.2, No.2.

Talika, F.T. (2016). Neliti, Inc (2017, September 2008). Diakses dari e-journal "Acta Diurna" Volume V. No.1. Tahun 2016: https:/www.neliti.com/public ations/92442/manfaatinternet-sebagai-mediakomunikasi-bagi-remaja-didesa-air-mangga-kecamat

Tekno.liputan6.com. (n.d.). Tekno.liputan6.com (2017, September 28). Diakses dari Liputan6 Website: https://www.liputan6.com/tek no/read/2634027/3-mediasosial-favorit-penggunainternet-indonesia

Thenextweb.com. (n.d.). Thenextweb.com (2017, September 28). Diakses dari from The Next Web Website: https://thenextweb.com/contri butors/2017/04/11/currentglobal-state-internet/
Walid. (2018). Penggunaan Instagram Sebagai Social Media Marketing Dalam Membangun Brand Awareness PLATBM1912 Di Kota Pekanbaru. JOM FISIP Vol. 5: Edisi 1 Januari - Juni 2018.

Yumna Aisyah, R. C. (2018). Pemanfaatan Media Online Beritajakarta.Id Dalam Publikasi Program Kerja Pemprov DKI Jakarta. Jurnal Avant Garde Volume VI Nomor 2, 42-56. 